\title{
Validation of a multi-source feedback tool for use in General Practice
}

John Campbell, Professor of General Practice and Primary Care, Associate Dean, Peninsula Medical School. GMC Lead investigator on MSF.

Ajit Narayanan, Professor, Head of School of Computing and Mathematical Sciences, Auckland University of Technology, New Zealand. Statistical consultant to GMC work on MSF

Bryan Burford, Senior Research Associate, School of Medicine and Health, Durham University. Northern Deanery lead researcher on multi-source feedback

Michael Greco, Director of CFEP Surveys, Innovation Centre, University of Exeter (author of the IPQ patient survey for UK General Practice) and Associate Professor, School of Medicine, Griffith University, Australia

Keywords Revalidation; Multi-source feedback; peer assessment; patient feedback 


\section{Summary}

Feedback from colleagues and patients is a core element of the revalidation process being developed by the General Medical Council. However, there are few tools which have been specifically developed and validated for doctors in primary care. This paper presents data demonstrating the reliability and validity of one such tool.

The CFEP360 tool combines feedback from the Colleague Feedback Evaluation Tool (CFET), and the Doctor's Interpersonal Skills Questionnaire (DISQ). The analysis of over 10,000 completed questionnaires presented here identifies that colleague feedback is essentially two-dimensional (clinical and non-clinical skills), and that patient feedback is one-dimensional. However, items from both scales also effectively predict combined global ratings, indicating that colleagues and patients are identifying similar levels of performance as accessed by the feedback. Doctors who receive low feedback scores may require further attention, meaning the feedback has potentially diagnostic value.

Reliable feedback on this tool, as indicated by this analysis, requires 14 colleague responses and 25 patient responses, figures comparable to other multi-source feedback tools if CFEP360 is to be used for a high-stake performance evaluation and possible revalidation (generalisability statistic $\mathrm{G} \geq 0.80$ ). For lower-stake performance evaluations, such as personal development, 11 colleagues and 16 patients will still return reliable results $(\mathrm{G} \geq 0.70)$. 


\begin{abstract}
What is already known in this area
Multi-source feedback - feedback on performance from colleagues and patients

- can be a useful tool in medical education and revalidation. It is identified as a key part of new revalidation processes in the UK.
\end{abstract}

What this work adds

The paper reports validation of a tool incorporating colleague and patient feedback, specifically designed for primary care.

\title{
Suggestions for future research
}

Further research could look in more detail at the influences on colleague and patient feedback, the acceptability of these tools to the target groups, and issues around the use of MSF for the revalidation of peripatetic sessional GPS and locums. 


\section{Validation of a multi-source feedback tool for use in General Practice}

\section{Introduction}

Multi-source feedback (MSF) has come a long way in medical education in recent years, from early explorations of peer assessment ${ }^{12}{ }^{3}$ to its current use at different stages of training and practice, in a number of countries ${ }^{4}$. In the UK MSF has become well established in Foundation Programme training ${ }^{5}$, increasingly in speciality training ${ }^{6}$ and is set to become a central component in the revalidation of all practicing doctors ${ }^{7}{ }^{8}$. While there are qualitative approaches to multi-source feedback and appraisal ${ }^{910}$, the dominant approach is that of questionnaires which are completed by a number of 'raters' to produce an aggregate score.

For high stakes usage, the requirements for such a tool to be reliable and valid are even more important than for more formative and lower stakes usage. In practice, reliability means that a stable and accurate assessment can be obtained ${ }^{11}$ while validity relates mainly to the appropriateness and sense of the tool's content, to the coherence of any underlying constructs it measures, and its relationship to other indicators ${ }^{12}$. Further influences on the effectiveness of feedback are in recipients' characteristics, such as their ability to reflect and whether they agree with $\mathrm{it}^{13}$, but the measurements must be robust and meaningful before such questions are addressed. 
Studies reporting the validation of tools in medical education have concentrated on the construct validity of the tools - ensuring that multiple-item scales are measuring relevant underlying constructs - and their reliability. Generalisability theory has been used to establish the required numbers of raters for reliable measurements ${ }^{14}$. The required number has been found to vary, with for example different tools reported to require 12 colleagues (various specialties) ${ }^{15}$, 22 patients and 8 colleagues (primary and secondary care) ${ }^{16}, 41$ patients, 6 clinical and/or 5 non-clinical colleagues (primary care) $)^{17}, 25$ patients and 13 colleagues (psychiatry) ${ }^{18}, 23$ patients, 10 medical and 7 non-medical colleagues (various specialties) ${ }^{19}$. Studies not using generalisability theory have been reported to require four colleague raters in paediatrics ${ }^{20}$, and six $^{21}$ or eight $^{22}$ raters for Foundation Programme trainees (across specialties) to reliably identify doctors presenting problems.

\section{Multi-source feedback in General Practice}

This paper describes the validation of a multi-source feedback tool for use in primary care settings. Little published research has been conducted with tools developed specifically for this environment, which differs from other clinical contexts both in the composition of teams (being smaller and with a different mix of clinical and non-clinical staff) and the nature of the patient interaction (being predominantly one-to-one, and with a more patient-driven agenda). There is evidence that the key competencies forming the focus for feedback differ between primary and secondary care settings ${ }^{23}$, although a tool used in 
both primary and secondary care settings found no difference between scores for doctors in each setting ${ }^{16}$.

MSF systems must be clear who is to provide feedback - whether raters will be drawn only from other doctors, or from colleagues in other clinical professions (such as nurses or pharmacists), non-clinical colleagues (clerks or receptionists) or patients. In general practice the inclusion of the patient is particularly pertinent, as while other clinicians have the expertise to assess clinical behaviour, they are rarely present during consultations. On the other hand, while patients provide a valuable first hand account of doctor performance, they lack clinical knowledge. Different relationships and areas of expertise mean that questions may need to cover different domains, and be phrased differently, for different groups.

For example, the Canadian Physician Achievement Review $\left(\mathrm{PAR}^{24}\right)$, largely developed in general practice ${ }^{25}$ consists of a number of questionnaires, with varying focus on clinical and non-clinical skills, for patients, medical colleagues and non-medical colleagues. It is now well established in a number of domains and has become a mandatory part of a revalidation programme ${ }^{26}$.

In the UK, Murphy and colleagues ${ }^{27}$ reported the evaluation of a number of assessments for general practice registrars which included colleague MSF and patient satisfaction. The MSF component consisted of just two items - one referring to professional behaviour, the other to clinical performance. Doctors' clinical colleagues were asked to complete both, while non-clinical colleagues were asked to complete just the item concerning professional behaviour. 
Patients received a separate tool ${ }^{28}$. The recipients of feedback reported that the colleague MSF was less feasible and acceptable compared to the patient satisfaction questionnaire and to other assessments such as criterion audit and significant event analysis. Both feedback tools were concluded to be sufficiently reliable for high-stakes use, and are currently used in the training of General Practitioners in the $\mathrm{UK}^{29}$.

Griffin et $\mathrm{al}^{30}$, also in the UK, describe an approach to MSF in general practice which addressed the potential contrast between individual performance, and the performance of the practice as a whole. Questions covered four categories of generic effective performance, with a fifth category of 'effective consulting skills' included for medical staff. A pilot study found the questions suitable for practice staff, but indications of low content validity and reports of the questions being hard to understand from patients. They did not draw clear conclusions on the usefulness of the tool in targeting at either individuals or practices.

The current study presents a 360-degree MSF tool combining feedback from two separate tools for the collection of peer and patient feedback. The Colleague Feedback Evaluation Tool (CFET) ${ }^{31}$ collects feedback from a doctor's colleagues on their clinical performance, communication and probity. The Doctor's Interpersonal Skills Questionnaire (DISQ) has been validated and well-studied on its own ${ }^{32}{ }^{33}$, and collects feedback from patients which focuses specifically on the interpersonal elements of the interaction. While not directly blueprinted $^{34}$, both tools reflect domains established by the General Medical 
Council, in its document Good Medical Practice ${ }^{35}$ and as such have good content validity.

The revalidation process in the UK has dual aims, both diagnostic and developmental. Tools such as those examined here should therefore be able to identify the small proportion of doctors who are underperforming, while still being of use to the vast majority of doctors with no major problems who must nonetheless complete the revalidation process. The GMC has produced guidelines for feedback tools to be suitable for the revalidation process. ${ }^{36}$

This paper reports findings on the reliability and construct validity of feedback collected on the CFET and DISQ as well as the use of the feedback for identifying potential problem doctors.

\section{Methods}

\section{The CFET (colleague) and DISQ (patient) questionnaires}

The Colleague Feedback Evaluation Tool (CFET) is a survey instrument used to collect feedback from a doctor's colleagues while the Doctor's Interpersonal Skills Questionnaire (DISQ) is used to collect feedback from patients. Table 1 summarises the content of both questionnaires. The CFET has 17 items describing specific doctor attributes, and one asking for an overall, or global, judgement. The DISQ patient questionnaire consists of 12 items including two global assessments. 
Responses to both questionnaires are on a 5-point scale with anchors 'Poor' (1)

to 'Excellent' (5) with an option for 'Don't know'. For the CFET, but not the DISQ,

the extremes of the scale are further defined with exemplars. For example, under 'Clinical Knowledge', the 'Poor' end of the scale is defined as "Does not keep knowledge up to date; misinformed", while 'Excellent' is defined as "Evidence aware; regularly updates knowledge".

Other information gathered using the CFET relates to whether a colleague is a doctor or 'other', and on the DISQ whether a patient is seeing a doctor for the first time, and the age of the patient. The gender of respondents is asked on both tools.

Table 1. Areas covered by CFET and DISQ items

\begin{tabular}{|c|c|}
\hline CFET items & DISQ items \\
\hline $\begin{array}{l}\text { 1. Clinical knowledge } \\
\text { 2. Clinical ability } \\
\text { 3. Communication with patients } \\
\text { 4. Compassion/empathy } \\
\text { 5. Communication with colleagues } \\
\text { 6. Punctuality and reliability } \\
\text { 7. Respect for colleagues } \\
\text { 8. Ability to say 'no'. } \\
\text { 9. Awareness of limitations } \\
\text { 10. Team orientation } \\
\text { 11. Use of resources } \\
\text { 12. Ability to manage stress } \\
\text { 13. Respect for confidentiality with patients and } \\
\text { 14. Appearance and behaviour } \\
\text { 15. Respect for their own health } \\
\text { 16. Trustworthiness/honesty/probity } \\
\text { 17. Management/leadership skills } \\
\text { 18. Overall ability as a doctor [global item] }\end{array}$ & $\begin{array}{l}\text { 1. Satisfaction with visit [global item] } \\
\text { 2. Warmth of greeting } \\
\text { 3. Listening skills } \\
\text { 4. Explanation skills } \\
\text { 5. Reassurance } \\
\text { 6. Confidence in ability } \\
\text { 7. Able to express concerns and fears } \\
\text { 8. Time in consultation } \\
\text { 9. Respect shown } \\
\text { 10. Patient's personal context } \\
\text { 11. Patient as a person } \\
\text { 12. Recommendation [global item] }\end{array}$ \\
\hline
\end{tabular}




\section{Participants}

Participating doctors had directly approached CFEP-UK Surveys, a professional health survey organisation, seeking an opportunity to undertake multi-source feedback using information derived from patients and colleagues. It was thus not possible to compare the characteristics of voluntary participants and nonparticipant doctors.

Consecutive patients attending the doctor receiving feedback were offered the DISQ by the practice receptionist on arrival. In the case of patients under the age of 16 , their parent or guardian would be offered the questionnaire. The patient was asked to complete the questionnaire after the consultation, and to post it in a sealed envelope (provided) in a box in the reception area.

The analysis presented in this paper used anonymised datasets derived from these volunteer samples.

\section{Analysis}

A detailed outline of the analysis is contained in the Appendix. In summary, the data was explored at two levels: unaggregated, at patient and colleague levels; and aggregated to the level of the index doctor.

Analysis took three approaches:

(i) Reliability was investigated using classical approaches (internal consistency, Cronbach's alpha) modified to deal with the uncrossed aspects of the study (raters provide only one rating and all raters may 
be different for every doctor), or using approaches based on generalisability theory ('G-study'). In the latter case, mathematical approaches to handling variation in the numbers of raters (unbalanced aspects of the study), or in the number of items rated, are outlined in detail in the appendix.

(ii) Hierarchical cluster analysis was used to investigate clustering of variables at various levels of data analysis, and principal components analysis was used to investigate the internal structure of the questionnaires.

(iii) Finally, data-fitting and predictive modelling of the combined patient and colleague feedback for each doctor using linear regression and the data-mining tool Cubist were carried out to identify variables which might be used alone or in combination to identify doctors whose performance may warrant further scrutiny.

\section{Results}

The data presented relates to feedback obtained regarding the performance of 179 general practitioners.

\section{CFET and DISQ unaggregated data profile}

Of 2421 colleague respondents completing the CFET, 768 (31.7\%) identified themselves as doctors, and 1569 (64.8\%) reported 'other' occupational status. 
Female respondents (1734, 71.6\%) predominated (males 497 (20.5\%), 190 (7.8\%) unspecified).

Table 2 gives descriptive statistics for each CFET item. Mean ratings for the items evaluated ranged from 3.88 to 4.61 , with an overall mean of 4.23 across all 18 items. All items had negative skewness, indicating a long tail to the left of the mean (lower values), with the peak to the right, reflecting favourable impressions of doctor performance. The proportion of responses using the bottom two scale descriptors ('Poor', 'Fair') averaged 4.3\% (0.7\%, 3.6\%), with the lowest use $(0.8 \%)$ for an item addressing respect shown to the patient, and highest (8.5\%) for an item relating to appearance and behaviour. For the global item, only $1.2 \%$ of colleagues used the bottom two descriptors.

Missing data (blank, unable to comment) ranged from <1\% ('Appearance and Behaviour') to $15 \%$ ('Clinical ability'), with overall mean $7.2 \%$ (standard deviation 4.3\%). Inter-item correlations ranged from 0.261 ('Compassion / Empathy' and 'Ability to say no') to 0.790 ('Compassion/ Empathy' and 'Communication with patients'). All inter-item correlations were significant at p<0.01 (2-tailed). 
Table 2. Descriptive statistics for CFET items

\begin{tabular}{|l|c|c|c|}
\hline CFET items & Mean & $\begin{array}{c}\text { Standard } \\
\text { deviation }\end{array}$ & Skewness \\
\hline 1. Clinical knowledge & 4.36 & 0.73 & -0.88 \\
\hline 2. Clinical ability & 4.33 & 0.74 & -0.84 \\
\hline 3. Communication with patients & 4.22 & 0.83 & -0.83 \\
\hline 4. Compassion/empathy & 4.21 & 0.83 & -0.79 \\
\hline 5. Communication with colleagues & 4.08 & 0.94 & -0.86 \\
\hline 6. Punctuality and reliability & 4.21 & 0.96 & -1.19 \\
\hline 7. Respect for colleagues & 4.14 & 0.94 & -0.96 \\
\hline 8. Ability to say 'no'. & 3.93 & 0.89 & -0.57 \\
\hline 9. Awareness of limitations & 4.21 & 0.75 & -0.66 \\
\hline 10. Team orientation & 3.96 & 0.95 & -0.72 \\
\hline 11. Use of resources & 4.22 & 0.76 & -0.72 \\
\hline 12. Ability to manage stress & 3.88 & 0.96 & -0.71 \\
\hline 13. Respect for confidentiality with patients and colleagues & 4.51 & 0.68 & -1.25 \\
\hline 14. Appearance and behaviour & 4.49 & 0.69 & -1.24 \\
\hline 15. Respect for their own health & 4.28 & 0.79 & -0.97 \\
\hline 16. Trustworthiness/honesty/probity & 4.61 & 0.63 & -1.47 \\
\hline 17. Management/leadership skills & 4.06 & 0.92 & -0.84 \\
\hline 18. Overall ability as a doctor [global item] & 4.38 & 0.71 & -0.95 \\
\hline
\end{tabular}

For DISQ there were 8474 patient responses. Females (5329, 63\%)

outnumbered males $(2938,35 \%)$ in almost a 2:1 ratio (2\% unspecified).

Descriptive statistics for each item are given in Table 3. Mean ratings ranged

from 3.98 to 4.40 , with an overall mean of 4.25 (standard deviation 0.85 ). All items had similar negative skewness to CFET items (CFET skewness average all items -0.91; DISQ skewness average all items -0.92), so patients' ratings therefore also reflect favourable impressions of doctor performance. 
Table 3. Descriptive statistics for DISQ items

\begin{tabular}{|l|c|c|c|}
\hline DISQ items & Mean & $\begin{array}{c}\text { Standard } \\
\text { deviation }\end{array}$ & Skewness \\
\cline { 1 - 1 } 1. Satisfaction with visit [global item] & 4.23 & 0.84 & -0.04 \\
\cline { 1 - 1 } 2. Warmth of greeting & 4.29 & 0.83 & 0.22 \\
\cline { 1 - 1 } 3. Listening skills & 4.32 & 0.83 & 0.64 \\
\cline { 1 - 1 } 4. Explanation skills & 4.26 & 0.84 & 0.07 \\
\cline { 1 - 1 } 5. Reassurance & 4.21 & 0.88 & 0.17 \\
\cline { 1 - 1 } 6. Confidence in ability & 4.33 & 0.83 & 0.58 \\
\cline { 1 - 1 } 7. Able to express concerns and fears & 4.24 & 0.86 & 0.29 \\
\cline { 1 - 1 } 8. Time in consultation & 4.40 & 0.79 & 0.69 \\
\cline { 1 - 1 } 10. Respect shown & 3.98 & 0.91 & -0.51 \\
\cline { 1 - 1 } 11. Patient's personal context as a person & 4.17 & 0.87 & -0.19 \\
\cline { 1 - 1 } 12. Recommendation [global item] & 4.21 & 0.87 & -0.04 \\
\hline
\end{tabular}

The proportion of responses using the bottom two scale descriptors averaged $3.3 \%(0.3 \%, 3 \%)$, with the lowest use $(1.9 \%)$ being for an item addressing respect shown to the patient, and highest (5.6\%) for 'adequacy of the length of the consultation'. For the global items 9 and 20, 2.9\% and $3.4 \%$ of patients used the bottom two descriptors. Missing data (blank, unable to comment) ranged from 1.2\% (Warmth of Greeting) to 3.7\% (Consideration of Personal Situation), with overall mean $2.2 \%$, standard deviation $0.8 \%$. Inter-item correlations ranged from 0.683 (Time given to patient and Confidence in doctor) to 0.857 (Doctor's explanation and Extent of reassurance). All inter-item correlations were significant at $p<.01$ level (2-tailed). 


\section{Reliability}

At the unaggregated level (i.e. the level of raw scores provided by raters irrespective of the doctor being rated) using 1557 fully completed CFET questionnaires and 7839 fully completed DISQ questionnaires, CFET was observed to have an internal consistency $(\alpha)$ of 0.84 after accounting for rater variance as a source of measurement error (Equation 1, Statistical Appendix), and a G coefficient of 0.80 after taking into account the interaction of rater with item and rater with ratee as sources of measurement error (Equation 2). Equivalent results for DISQ were 0.95 and 0.89 (Table 4; see Statistical Appendix for further details). 
Table 4. Calculations of alpha and G coefficients for CFET and DISQ data at the unaggregated and aggregated levels. See Statistical Appendix for detail.

\begin{tabular}{|c|c|c|c|c|}
\hline \multirow{2}{*}{$\begin{array}{c}\text { CFET } \\
\text { Unaggregated }\end{array}$} & & \multicolumn{3}{|c|}{ DISQ } \\
\hline & & $\begin{array}{c}\% \\
\text { variance }\end{array}$ & & $\begin{array}{c}\% \\
\text { variance }\end{array}$ \\
\hline $\begin{array}{l}\text { Number of fully } \\
\text { completed } \\
\text { questionnaires }\end{array}$ & 1557 & & 7839 & \\
\hline Number of items & 17 & & 10 & \\
\hline $\begin{array}{l}\text { Average item } \\
\text { variance } \\
\bar{v}_{i}\end{array}$ & 0.67 & $51 \%$ & 0.72 & $73 \%$ \\
\hline $\begin{array}{c}\text { Average item } \\
\text { covariance } \bar{a}\end{array}$ & 0.32 & & 0.56 & \\
\hline $\begin{array}{l}\text { Average rater } \\
\text { variance } \bar{v}_{r}\end{array}$ & 0.39 & $29 \%$ & 0.15 & $15 \%$ \\
\hline $\begin{array}{c}\bar{v}_{i} \times \bar{v}_{r} \\
\text { Revised reliablity }\end{array}$ & 0.26 & $20 \%$ & 0.11 & $12 \%$ \\
\hline$\underset{\alpha^{\prime}}{\text { (Equation 1) }}$ & 0.84 & & 0.95 & \\
\hline $\begin{array}{l}\text { Revised G coefficient } \\
\qquad \text { (Equation 2) } G_{U}\end{array}$ & 0.8 & & 0.89 & \\
\hline $\begin{array}{c}\text { CFET } \\
\text { Aggregated }\end{array}$ & & & DISQ & \\
\hline Number of doctors & 179 & $\begin{array}{c}\% \\
\text { variance }\end{array}$ & 179 & $\begin{array}{c}\% \\
\text { variance }\end{array}$ \\
\hline Number of items & 17 & & 10 & \\
\hline $\begin{array}{l}\text { Aggregate average } \\
\text { doctor variance } \\
\qquad a \bar{v}_{d}\end{array}$ & 0.13 & $19 \%$ & 0.06 & $21 \%$ \\
\hline $\begin{array}{l}\text { Aggregated average } \\
\text { item variance } \\
\qquad \bar{v}_{i}\end{array}$ & 0.17 & $25 \%$ & 0.07 & $25 \%$ \\
\hline $\begin{array}{c}\text { averager rater } \\
\text { variance } \bar{v}_{r}\end{array}$ & 0.39 & $56 \%$ & 0.15 & $54 \%$ \\
\hline Revised aggregated & & & & \\
\hline $\begin{array}{l}\text { G coefficient } \\
\text { (Equation 3) } \\
G_{A}\end{array}$ & 0.82 & & 0.92 & \\
\hline
\end{tabular}




\section{Hierarchical cluster analysis}

Hierarchical cluster analysis of CFET revealed early clustering of items 1 and 2 with 18, and items 3 and 4 . Clustering patterns were also evident between items 7, 10, and 5, and between 12, 15 and 8 . These patters of clustering were evident at both aggregated (i.e. when the raters' raw scores for a doctor were averaged across items to result in an overall profile of scores for that doctor) and unaggregated levels of data analysis (Figure 1). Hierarchical cluster analysis of DISQ revealed clustering of items 10, 11 and 12, 4 and 5, and 2 and

3. Items 9 and 1 were outliers, not showing evidence of early clustering at either level of data analysis (Figure 2). 

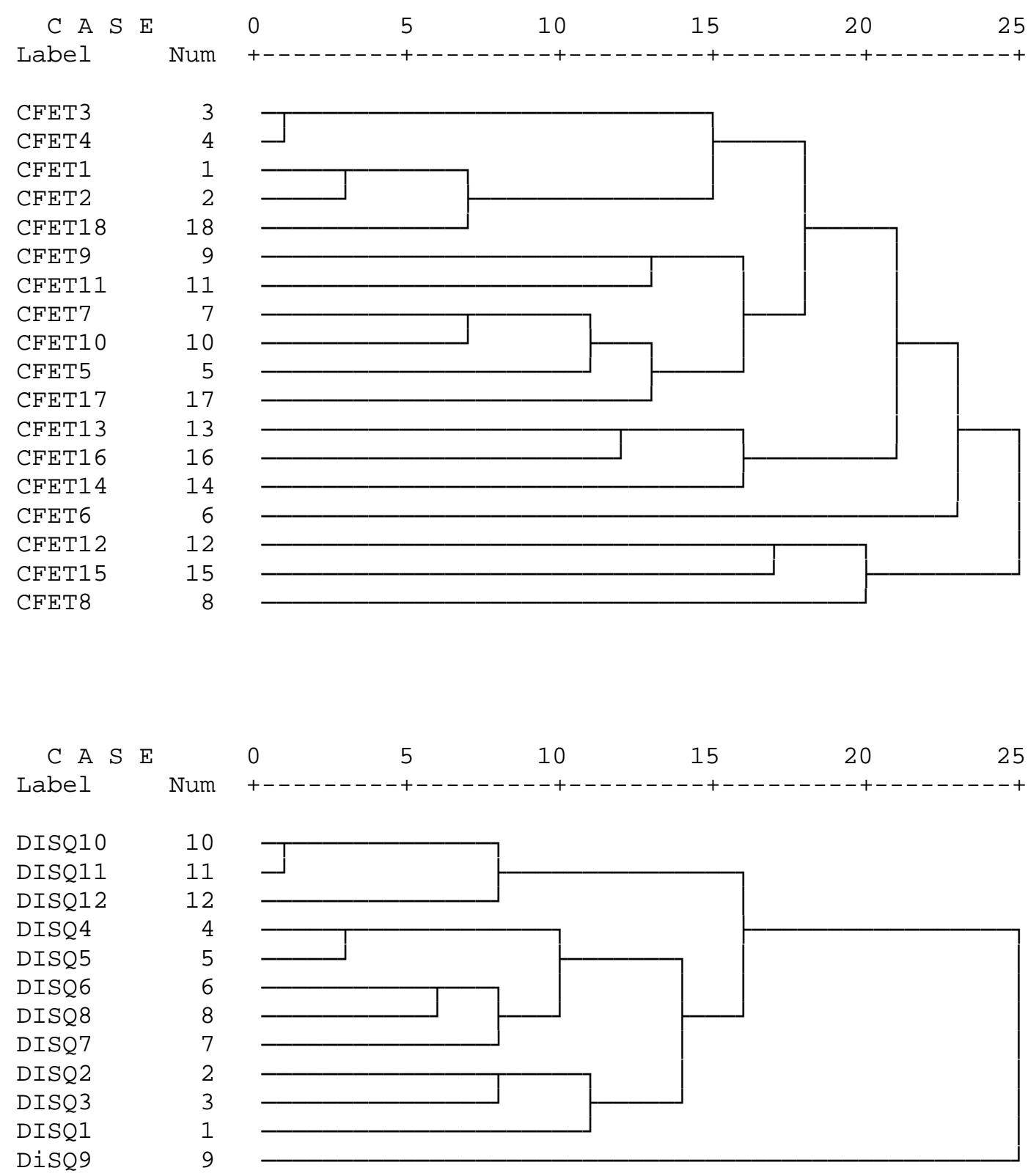

Figure 1: Hierarchical cluster analysis of all CFET items (top dendogram) and DISQ items (bottom dendogram), identifying the clustering order in which items combine using Pearson correlation as the distance measure. Figure 2 provides dendograms for the aggregated versions of these items. 


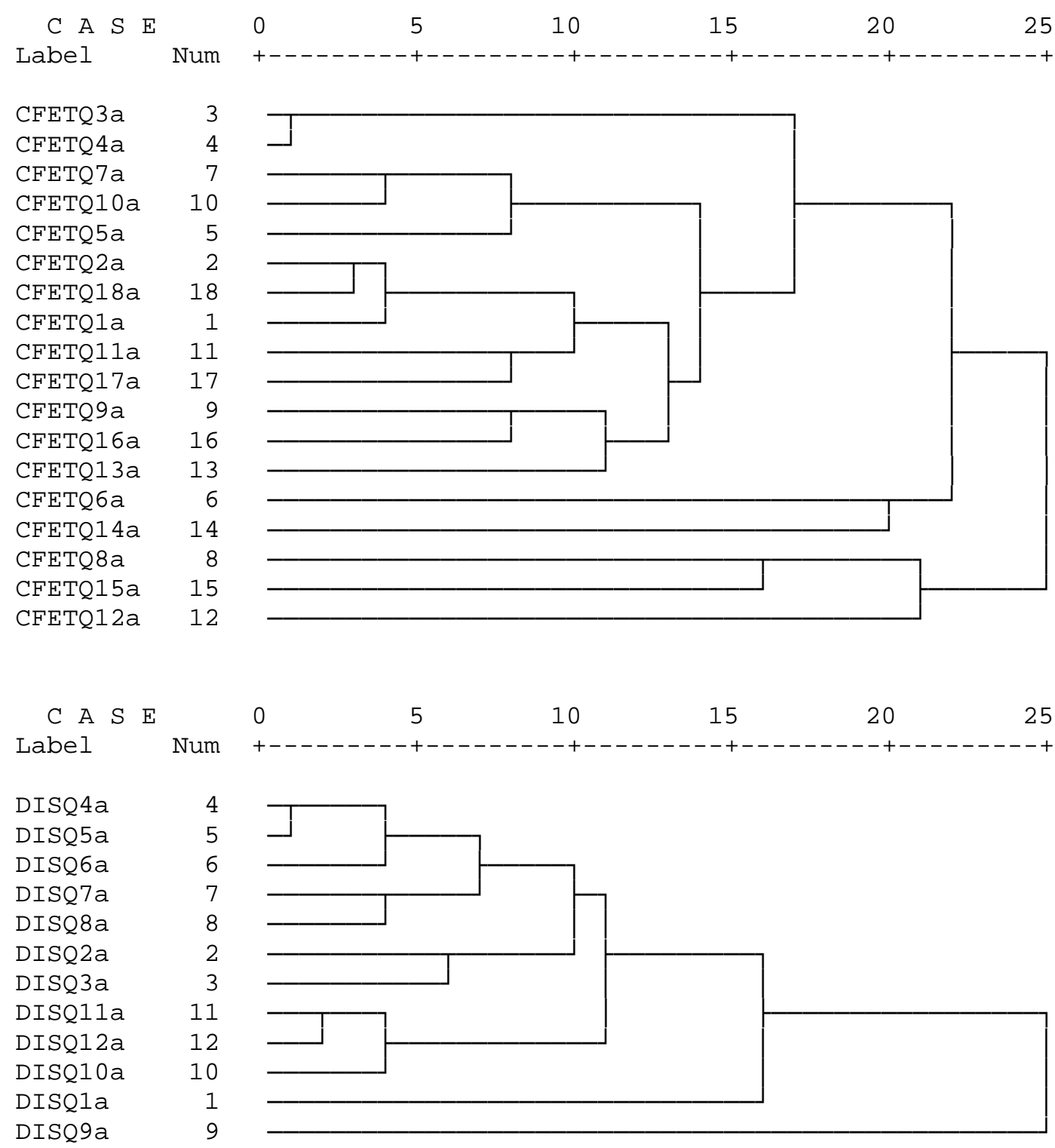

Figure 2: Hierarchical cluster analysis of all aggregated CFET items (top dendogram) and aggregated DISQ items (bottom dendogram), identifying the clustering order in which items combine using Pearson correlation as the distance measure. The suffix ' $a$ ' at the end of each item signifies that these are the aggregated versions of the unaggregated items depicted in Figure 1. 
This analysis demonstrates that the questionnaire structures are broadly preserved at both aggregated and unaggregated levels (Figures 1 and 2), with differences occurring in the strength of the relationships between items. For CFET, item 9 ('Awareness of limitations') moved from clustering with item 11 ('Use of resources') at the unaggregated level to clustering with item 16 ('Trustworthiness') at the aggregated level. For DISQ, item 14 ('Confidence in doctor's ability') was clustered with item 16 (Respect) at the unaggregated level but clustered with items 12 and 13 ('Doctor's explanations', 'Extent of reassurance') at the aggregated level. This preservation of structure indicates that the way individual raters structure their responses to doctors, as given by inter-item relationships, is maintained when these individual ratings are aggregated by doctor, demonstrating consistency of interpretation by all raters irrespective of doctor rated. Also, the aggregated HCA (bottom parts of Figures 1 and 2) incorporated all colleague and patient responses and not just the fully completed responses used for the unaggregated HCA (top parts of Figures 1 and 2). In other words, the addition of 867 colleague responses and 635 patient responses at the aggregated level has not affected the questionnaire structures when comparing the unaggregated and aggregated HCA.

\section{Internal structure}

Principal component analysis was used to see if the variance in questionnaire items can be explained by a smaller number of components. Given the consistency in inter-item relationships at both levels of analysis demonstrated 
by HCA, the expectation is that a principal component analysis would also reveal consistent components at both levels. At the unaggregated level, principal component analysis was undertaken on the 2421 CFET colleague responses in respect of 179 doctors, using all items except for the global item (17 items in total) and excluding list-wise any response that contained missing values (1557 responses in total). The analysis was repeated using mean values for these 17 CFET items at the aggregated level. At both levels two components were found (eigenvalue $>1.0$ ) that accounted for $59 \%$ of the variance $(52 \%$ for the first component, $7 \%$ for the second component) at the unaggregated level and $66 \%$ (55\% for the first component, $11 \%$ for the second component) at the aggregated level. Table 5 provides an overview of the component loadings and the way they changed from one level of analysis to the other.

For DISQ, only one component was found for the 10 non-global items at both the unaggregated (7839 full responses out of 8474) and aggregated levels, accounting for $81 \%$ and $94 \%$ of the variance respectively, and indicating that DISQ is unidimensional at both levels. These results provide further evidence that the questionnaire structure is reliable for both raters and ratees and remains broadly unaffected by adding responses with missing values.

Table 5. CFET Unaggregated and aggregated principal component analysis showing majority rotated component loadings only. 


\begin{tabular}{|c|c|c|c|c|}
\hline Factor analysis & $\begin{array}{l}\text { Unaggregated } \\
\text { component } 1 \\
\end{array}$ & $\begin{array}{l}\text { Unaggregated } \\
\text { component } 2\end{array}$ & $\begin{array}{c}\text { Aggregated } \\
\text { component } 1\end{array}$ & $\begin{array}{c}\text { Aggregated } \\
\text { component } 2\end{array}$ \\
\hline Q1. Clinical knowledge & .679 & & .685 & \\
\hline Q2. Clinical ability & .748 & & .784 & \\
\hline $\begin{array}{l}\text { Q3. Communication with } \\
\text { patients }\end{array}$ & .848 & & .893 & \\
\hline $\begin{array}{l}\text { Q4. Compassion/ } \\
\text { Empathy }\end{array}$ & .841 & & .910 & \\
\hline $\begin{array}{l}\text { Q5. Communication with } \\
\text { colleagues }\end{array}$ & .644 & & .752 & \\
\hline $\begin{array}{l}\text { Q6. Punctuality and } \\
\text { reliability }\end{array}$ & & .569 & & .630 \\
\hline $\begin{array}{l}\text { Q7. Respect for } \\
\text { colleagues }\end{array}$ & .613 & & .699 & \\
\hline Q8. Ability to say "no" & & .747 & & .749 \\
\hline $\begin{array}{l}\text { Q9. Awareness of } \\
\text { limitations }\end{array}$ & & .633 & & .638 \\
\hline Q10. Team orientation & .585 & & .703 & \\
\hline Q11. Use of resources & & .581 & .608 & \\
\hline $\begin{array}{l}\text { Q12. Ability to manage } \\
\text { stress }\end{array}$ & & .684 & & .625 \\
\hline $\begin{array}{l}\text { Q13. Respect for } \\
\text { confidentiality with } \\
\text { patients and colleagues }\end{array}$ & . & .580 & .555 & \\
\hline $\begin{array}{l}\text { Q14. Appearance and } \\
\text { behaviour }\end{array}$ & & .621 & & .645 \\
\hline $\begin{array}{l}\text { Q15. Respect to their } \\
\text { own health }\end{array}$ & & .776 & & .822 \\
\hline $\begin{array}{l}\text { Q16. Trustworthiness/ } \\
\text { honesty/ probity }\end{array}$ & .519 & & .625 & \\
\hline $\begin{array}{l}\text { Q17. Management/ } \\
\text { leadership skills }\end{array}$ & .560 & & .597 & \\
\hline
\end{tabular}

\section{CFET and DISQ aggregated data profile and analysis}

For CFET, the 179 doctors had an average of 14 questionnaires completed by colleagues (minimum 7, maximum 17) using all 2421 colleague responses.

Across 18 items, the mean score was 4.22 (range 3.88 to 4.60 ). The 18 -item summed scale average for doctors was 75.9 (standard deviation 5.4) out of a 
maximum possible score of 80.0 , and 71.5 if item 18 (the global item) was not included. A bivariate (Pearson) correlation between the scale score of all 17 non-global items against the global item 18 was highly significant $(r=0.881$, $\mathrm{p} \leq 0.001$ ), indicating a clear linear association between the non-global and global items.

For DISQ, the 179 doctors had an average of 47 questionnaires completed by patients (minimum 39, maximum 68) using all 8474 patient responses, with item means being 4.24 (minimum 4.00 and maximum 4.40). The 12 -item scale average for doctors was 50.91 (standard deviation 3.00) and 42.39 (2.49) if the two global items were not included. A bivariate (Pearson) correlation between the non-global, 10 item scale score and the two global items 9 and 20 was highly significant ( $r=0.949, r=0.964, p \leq 0.001$ in both cases), again indicating strong and clear linear associations between the non-global and global items.

\section{Modelling}

The two aggregated files were merged using the individual practitioner identifier as the key variable, resulting in a combined file for each doctor of 32 items (18 CFET items plus CFET scale, 12 DISQ items plus DISQ scale).

A hierarchical cluster analysis of all 32 items using Pearson correlation as the distance measure produced a dendrogram (Figure 3) that clearly separated the two measurement tools: all CFET items were located in a distinct part of the tree from all the DISQ items. The unidimensional nature of DISQ items was also clearly demonstrated in the way they clustered together tightly. 


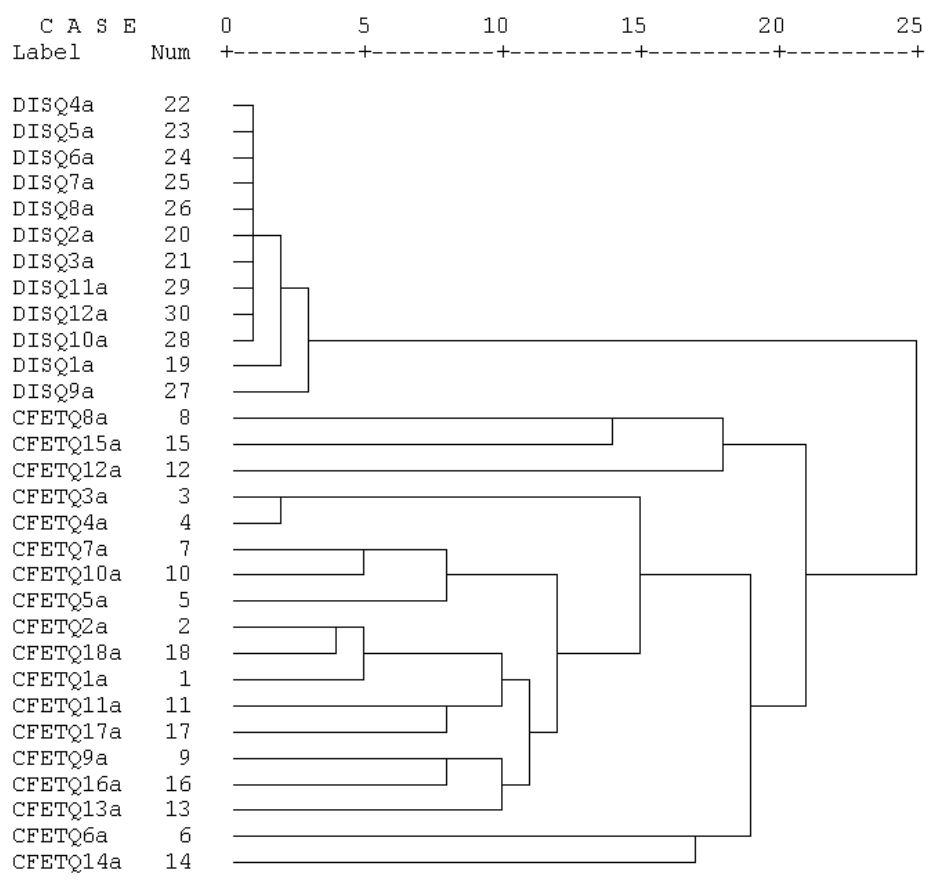

Figure 3: Hierarchical cluster analysis of all 32 aggregated items in the CFETDISQ 360, using Pearson correlation as the distance measure (rescaled). The dendrogram clearly shows that all DISQ items (DQ1-DQ12) and CFET items (CQ1-CQ18) occupy separate subparts of the tree.

A principal component analysis of the 17 CFET items and 10 DISQ items (excluding the global items) requesting only two components to check on the independence of the two questionnaires confirmed that the structural integrity of the CFET and DISQ components was preserved in the multisourced view. Each of the rotated components explained almost the same amount of variance (38\% for component 1, 33\% for component 2). The CFET and DISQ scales formed from the non-global items were then standardised and a paired samples t-test used to compare the scores obtained by a doctor on the two scales, resulting in a weak 0.353 correlation ( $p \leq 0.001$ ) and no significant difference between the two scale values. In other words, patients and colleagues agree to some extent 
in their views of the same doctor. Also, a very strong correlation between DQ9 and DQ20 (.912, p $\leq 0.001)$ indicates that these two global items could be merged into one global item for modelling purposes (below).

Three methods were adopted for modelling doctors in the multisourced data: (a) a standards-based approach using all non-global items; (b) a stepwise linear regression using a data fitting model and the three global items; and (c) crossvalidated linear predictive modelling using a combined CFET/DISQ scale and the three global items.

\section{a) Standards based approach}

A standards-based approach adopts standardised values (each variable recalculated with mean 0 and all variable values expressed as positive and negative standard deviations from the mean) where the percentage of values expected to lie in the symmetric confidence interval \pm 1.96 standard deviations is 95\%. Table 6 identifies those 55 doctors whose standardised, non-global item values are $\leq-1.96$ and therefore can be regarded as falling in at least the bottom $2.5 \%$ of performance on one or more items if these are normally distributed. Since items are negatively skewed, the use of the -1.96 threshold will find those doctors at the extreme end of the long tail for each item. A standards-based approach should be used with caution on skewed data. Nevertheless, if a doctor is falling in the long tails of several items both within and across sources, this may be an appropriate trigger to considering further investigation of that doctor's performance. 
Using a standards-based approach to modelling of the data identified almost one third of doctors whose performance on at least one of the [30] items was at least -1.96 standard deviations below the norm for this sample. In the context of a total number of available average ratings ( $n=5370,30$ such ratings for each of the 179 doctors), 137 "outlying" performances were attributable to outlying average ratings on CFET items, whilst 68 were attributable to outlying averages on DISQ items (Table 6). This ratio of almost 2:1 could result from CFET containing almost twice the number of items as DISQ, or may suggest that colleagues are more critical of a doctor's performance than are patients.

Table 6. Stepwise regression on the three global items using all non-global items (CFET and DISQ separately). No constant was used in the model.

\begin{tabular}{|c|c|c|c|c|c|c|}
\hline $\begin{array}{l}\text { All other CFET } \\
\text { items against } \\
\text { global item } \\
\text { (Q18) }\end{array}$ & $\begin{array}{l}\text { Adjusted R } \\
\text { Square }\end{array}$ & Item & $\begin{array}{l}\text { Std. } \\
\text { Error }\end{array}$ & $\begin{array}{c}\text { Standardized } \\
\text { Beta }\end{array}$ & $t$ & Sig. \\
\hline & 0.999 & CFETQ2 & 0.061 & 0.305 & 5.11 & 0.000 \\
\hline & & CFETQ10 & 0.028 & 0.146 & 5.71 & 0.000 \\
\hline & & CFETQ16 & 0.043 & 0.111 & 2.46 & 0.015 \\
\hline & & CFETQ3 & 0.032 & 0.168 & 5.50 & 0.000 \\
\hline & & CFETQ1 & 0.051 & 0.207 & 4.08 & 0.000 \\
\hline & & CFETQ14 & 0.031 & 0.065 & 2.06 & 0.041 \\
\hline \multirow[t]{7}{*}{$\begin{array}{l}\text { All other non- } \\
\text { global DISQ } \\
\text { items against } \\
\text { first global } \\
\text { item (Q9) }\end{array}$} & & & & & & \\
\hline & 0.999 & DISQQ3 & 0.089 & 0.247 & 2.73 & 0.007 \\
\hline & & DISQQ10 & 0.093 & 0.278 & 3.02 & 0.003 \\
\hline & & DISQQ2 & 0.072 & 0.283 & 3.88 & 0.000 \\
\hline & & DISQQ6 & 0.074 & 0.240 & 3.18 & 0.002 \\
\hline & & DISQQ9 & 0.067 & 0.138 & 2.21 & 0.029 \\
\hline & & DISQQ11 & 0.089 & -0.186 & -2.10 & 0.037 \\
\hline \multirow[t]{4}{*}{$\begin{array}{l}\text { All other non- } \\
\text { global DISQ } \\
\text { items against } \\
\text { second global } \\
\text { item (Q20) }\end{array}$} & & & & & & \\
\hline & 0.999 & DISQQ11 & 0.072 & 0.412 & 5.82 & 0.000 \\
\hline & & DISQQ6 & 0.057 & 0.322 & 5.55 & 0.000 \\
\hline & & DISQQ10 & 0.070 & 0.266 & 3.91 & 0.000 \\
\hline
\end{tabular}




\section{b) Stepwise regression}

Stepwise regression only introduces a variable into a model if it is significant $(p \leq 0.05)$ and is useful for selecting the minimal subset of variables required to predict an independent variable. A stepwise linear regression through the origin (constant not included on the assumption that no independent variable would be zero due to its aggregation) that initially included all CFET and DISQ non-global items (independents) on CFET and DISQ global items (dependents) resulted in highly successful models (Table 7) using subsets of items, with almost perfect prediction (99.9\%). The standardised beta coefficients provide an indication of the relative influence of the selected non-global items.

Table 7. Decision study experiments with CFET using Equation 4, using all variance components from the original data set. The underlined reliability score represents the R actually calculated for CFET at the aggregated level. (See Statistical Appendix for further details.)

\begin{tabular}{|c|c|c|c|c|c|c|c|c|}
\hline CFET & & & & Raters & & & & \\
\hline Items & $\mathbf{1 0}$ & $\mathbf{1 1}$ & $\mathbf{1 2}$ & $\mathbf{1 3}$ & $\mathbf{1 4}$ & $\mathbf{1 5}$ & $\mathbf{1 6}$ & $\mathbf{1 7}$ \\
\hline $\mathbf{1 1}$ & 0.76 & 0.81 & 0.85 & 0.90 & 0.93 & 0.97 & & \\
\hline $\mathbf{1 2}$ & 0.74 & 0.78 & 0.83 & 0.87 & 0.91 & 0.95 & 0.98 & \\
\hline $\mathbf{1 3}$ & 0.72 & 0.77 & 0.81 & 0.85 & 0.89 & 0.92 & 0.96 & 0.99 \\
\hline $\mathbf{1 4}$ & 0.70 & 0.75 & 0.79 & 0.83 & 0.87 & 0.90 & 0.94 & 0.97 \\
\hline $\mathbf{1 5}$ & 0.69 & 0.73 & 0.78 & 0.82 & 0.85 & 0.89 & 0.92 & 0.95 \\
\hline $\mathbf{1 6}$ & 0.68 & 0.72 & 0.76 & 0.81 & 0.84 & 0.87 & 0.91 & 0.94 \\
\hline $\mathbf{1 7}$ & 0.66 & 0.71 & 0.75 & 0.79 & $\underline{0.82}$ & 0.86 & 0.89 & 0.92 \\
\hline
\end{tabular}




\section{c) Linear predictive modelling}

Finally, the 27 non-global items were tested for their accuracy in predicting all three global variables summed to form a total global score. On the 10-fold cross-validation using Cubist (a model is constructed using a random $90 \%$ of doctors and then tested on the remaining $10 \%$ of doctors in each fold), the overall mean predictive error for the total global score across all folds was 0.133, equivalent to $3 \%$ error in the range 10.35 to 14.46 (mean of summed global variables $=12.889)$. For the rule produced by Cubist when all samples were input for maximum rule gain, see the web pages

$$
\begin{aligned}
& \text { Total global score }=-0.504+0.82 \text { DISQQ14 + } 0.78 \text { DISQQ18 + } \\
& 0.41 \text { CFETQ2 + } 0.29 \text { CFETQ10 + } 0.37 \text { DISQQ11 + } 0.31 \\
& \text { DISQQ19 + } 0.18 \text { CFETQ1 }
\end{aligned}
$$

The weightings of the items provide an indication of their impact for predicting the combined global value. To check whether the inclusion of two DISQ global items was skewing the results, the analysis was re-run using a new item ('Total Global $_{2}{ }^{\prime}$ ) that was the sum of the global CFET item and the average of the two global DISQ items. The overall average predictive error for 'Total Global ${ }_{2}$ ' across all folds was 0.11 , equivalent to $4 \%$ error in the range (mean of summed global variables $=8.63$, range 6.76 to 9.66 ). For the rule produced by Cubist when all samples were input for maximum rule gain, see the web pages:

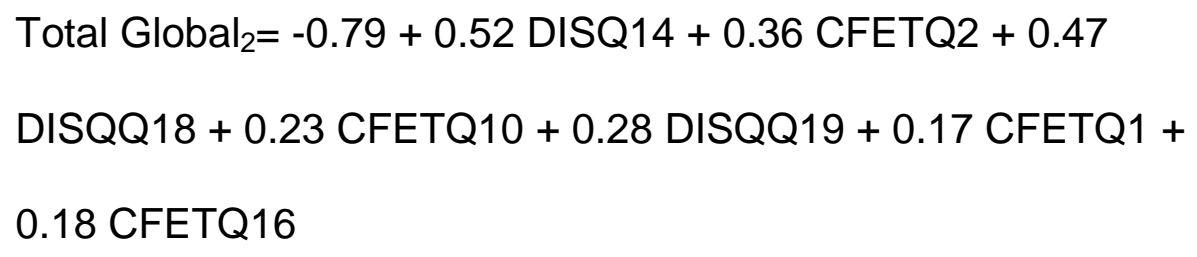




\section{Generalisability and required numbers of raters}

Inspection of the variance components (Table 4) indicates that, at the unaggregated level, colleague responses account for nearly twice as much variance (29\%) as patient responses (15\%). CFET items vary less than DISQ items (51\% as opposed to $73 \%$ variance). These differences in rater and item variance components are smoothed out at the aggregated level, where the variance components contributed roughly the same on each of the tools. Reliability, unaggregated and aggregated G coefficients for CFET $(0.84,0.80$ and 0.82 , respectively) and DISQ $(0.95,0.89$ and 0.92 , respectively) indicate that the results are robust even under uncrossed (raters do not rate the doctor on more than one occasion), unbalanced (doctors have different numbers of raters) and fully nested (each doctor's raters are specific to that doctor and not shared with any other doctor) conditions. These coefficients were calculated without the need to convert the unbalanced design into a balanced design through, for example, the removal of responses above a certain arbitrary number.

Decision (D) studies with CFET indicated that the absolute minimum number of colleague raters to achieve a reliability of 0.80 was 11 provided that only 11 CFET items were used (Table 8). However, the D-study also shows that only 14 colleague responses are required to produce a G-coefficient of 0.82 (with 13 colleagues $\mathrm{G}=0.79)$. 
Table 8. Hypothetical D study showing the effects of different numbers of average raters per doctor. (See Statistical Appendix for further details.)

\begin{tabular}{|c|c|c|}
\hline $\begin{array}{c}\text { Experimental } \\
\text { decidability }\end{array}$ & $\begin{array}{c}\text { Hypothetical } \\
\text { number of } \\
\text { average } \\
\text { raters per } \\
\text { doctor }\end{array}$ & $\begin{array}{c}\text { Hypothetical } \\
\mathbf{R}\end{array}$ \\
\hline DISQ & 30 & 0.84 \\
\hline & 25 & 0.81 \\
\hline & 20 & 0.77 \\
\hline & 15 & 0.69 \\
\hline
\end{tabular}

For DISQ, experiments were carried out with Equation 4 to determine D-study predictions for different response averages. Table 9 provides an overview of what would have happened to $G$ if the actual average number of raters had been lower than 47 but the variance components had remained the same as for 47 raters on average (i.e. current average of 47 included as part of the error). Dstudy predictions 'bottom out' at 0.81 at an average of 25 patient responses per doctor. Below this figure, the variance and error components contributed by an average of 47 raters per doctor overtake the contributions made by raters, using 0.8 as the threshold for reliability. In other words, for the variance present in the current data, 25 patient ratings is the absolute minimum number of samples required to produce a reliable assessment of a doctor, even if the average number of responses is significantly higher originally. All G- and D-studies were conducted on the non-global items only. 


\section{Discussion}

Results show that the CFEP360 tool, incorporating the DISQ patient feedback and the CFET colleague feedback questionnaires, has reliability and construct validity. Reliability analysis shows good internal consistency and a robust item structure, while generalisability and D-studies show the numbers required for reliable completion - 14 colleagues and 25 patients - are feasible in practice, and comparable to other tools in the same domain.

The combined tool is structurally sound, with the colleague and patient questionnaires producing robust component structures - two for the colleague questionnaire, one from patients. The separation of components is maintained when the data are aggregated. Construct validity can be inferred from these results, and the separation of components is evidence for the complementary nature of colleague and patient views.

Principal components analysis of CFET items identified two components. The first encompassed nine items which might be judged to reflect a doctor's contribution to clinical and team performance while the second encompassed six items relating to personal attributes, self-awareness, and the health status of the doctor being assessed. This reflects established findings in the literature that feedback corresponds to broadly 'clinical' and 'non-clinical' dimensions ${ }^{22} 37$. Loadings for two items ('use of resources' and 'respect for the confidentiality of patients and colleagues') varied between aggregated and unaggregated levels, and were thus less clearly attributable to either of the two components. 
Linear regression found that the questionnaire items relating to specific skills predicted global responses, indicating the validity of the items. For colleagues' global assessments of doctor's performance, the two most influential contributory independent predictors were (in order of standardised beta coefficients) items relating to the assessment of clinical ability and to the assessment of clinical knowledge. For patients' global assessments, four items (warmth, consideration, listening, and confidence in the doctor's ability) were of broadly similar influence as independent predictors of overall satisfaction, whereas the doctor's concern for the patient as a person was clearly of more influence as a predictor of the likelihood of recommending the doctor. This shows that while DISQ initially appears to be unidimensional, there is a substructure present and patient responses are nuanced by different elements of the interaction.

Finally, the multi-source predictive model using all colleague and patient feedback for each doctor identified two rules that used subsets of items for predicting to the three global items. A global assessment of a doctor's performance could be confidently predicted through measuring only these subsets of items which overlap with those identified in stepwise linear regression as independent predictors of a doctor's performance.

These results indicate that a multi-source analysis results in the identification of predictive items that are themselves subsets of items found in analysis of separate data-sets drawn from the two questionnaires. In other words the reasons for global doctor performance in separate datasets are also reasons for 
global performance when those data-sets are combined - separate colleague and patient ratings combine effectively as predictors of combined global ratings. We are not aware that this has been demonstrated before.

\section{Conclusion}

The analysis indicates that a doctor's performance as assessed using three global assessment items can be determined with $96 \%$ accuracy using responses to patient or colleague feedback on patient responses (confidence in the doctor's ability, consideration, ability to listen to patients and showing concern), and colleague responses (evaluation of clinical ability, team orientation and evaluation of clinical knowledge). Reliability and generalisability coefficients at both the aggregated and unaggregated levels indicate that the questionnaires are fit for purpose, even when taking into account that the rater is the main source of error in the uncrossed, fully nested and unbalanced design we adopted. The decision study results (using $0.8 \mathrm{G}$ coefficient as the threshold) indicate that, based on the average number of rater responses in this study, 14 colleague responses and 25 patient responses are the minimum required for a reliable assessment of a doctor's professional behaviour and practice when using the CFET and DISQ instruments respectively.

\section{Limitations of Study}

Participants receiving feedback were a self-selecting sample which may bias the results. Also, only $64 \%$ of colleague responses could be used at the 
unaggregated level due to missing values on one or more items. However, with no evidence to indicate that these doctors would have a particularly different mix of patients and colleagues, there is no suggestion that the statistical findings would be different with a wider sample. A further study may be required to determine whether missing values from colleagues are caused by a reluctance to award a negative judgement on overall ability of the doctor.

\section{Ethical approval}

Approval to collect multi-source feedback was given by the Chair of the North and East Devon Ethics Committee. For the purpose of evaluation such as the analysis here, no further ethical approval is required according to the NHS Research Governance framework ${ }^{38}$.

\section{Acknowledgements}

The authors acknowledge the contribution of the many respondents to the surveys, and the doctors who volunteered to take part. In addition, we would like to thank Wilson Wong for his initial work on the psychometric properties of the CFET and DISQ.

\section{Sources of funding}

No specific funding was obtained for this study. 


\section{Conflict of interest}

Michael Greco is a director of CFEP UK Surveys, which administers the CFET and DISQ tools.

\section{References}

1 Cuttino, JT \& Scatliff, JH. Resident performance evaluation. Investigative Radiology 1987 22: 986-989

2 Ramsey, PG, Wenrich, MJ, Carline, JD, Inui, TS, Larson, EB, Logerfo, JP. Use of peer ratings to evaluate physician performance. JAMA 1993. 269; $1655-1660$

3 Violato C, Marini A, Toews J, Lockyer J, Fidler H. Using peers, consulting physicians, patients, co-workers and self to assess physicians. Academic Medicine 1997; 70: 57-63

4 Wood, L, Hassell, A, Whitehouse, A, Bullock, A \& Wall, D. A literature review of multi-source feedback systems within and without health services, leading to 10 tips for their successful design. Medical Teacher. 2006. 28(7); e185e191

5 http://www.foundationprogramme.nhs.uk/pages/foundation-doctors/trainingand-assessment

6 Davies, H, Archer, J, Bateman, A, Dewar, S, Crossley, J, Grant, J \& Southgate, L. Specialty-specific multi-source feedback: assuring validity, informing training. Medical Education. 2008 42; 1014-1020 
7 Chief Medical Officer for England. Medical Revalidation - Principles and Next Steps London: Department of Health 2008 [http://www.dh.gov.uk/publications]

8 Crossley J, Davies H, McDonnell J, Cooper C, Archer JC, McAvoy P. A district hospital assessing its doctors for re-licensure: can it work? Medical Education 2008;42:359-363.

9 McClellan, H, Bateman, H \& Bailey, P. The place of 360 degree appraisal within a team approach to professional development. Journal of Interprofessional Care 2005. 19; 137-148

${ }^{10}$ Garbett, R, Hardy, S, Manley, K, Titchen, A \& McCormack, B. Developing a qualitative approach to 360-degree feedback to aid understanding and development of clinical expertise. Journal of Nursing Management 2007. 15; $342-347$

${ }^{11}$ Downing, SM. Reliability: on the reproducibility of assessment data. Medical Education 2004 38; 1006-1012

12 Downing, SM. Validity: on meaningful interpretation of assessment data. Medical Education 2003 37; 830-837

${ }^{13}$ Sargeant, J, Mann, K, Sinclair, D, van der Vleuten, C, Metsemakers, J. Understanding the influence of emotions and reflection upon multi-source feedback acceptance and use. Advances in Health Sciences Education 2008 $13 ; 275-288$

${ }^{14}$ Crossley, J, Davies, H, Humphris, G \& Jolly, B. Generalisability: a key to unlock professional assessment. Medical Education. 2002 36; 972-978 
${ }^{15}$ Wilkinson, JR, Crossley, JGM, Wragg, A, Mills. P, Cowan, G \& Wade, W. Implementing workplace-based assessment across the medical specialties in the United Kingdom. Medical Education 2008 42; 364-373

${ }^{16}$ Campbell, JL, Richards, SH, Dickens, A, Greco, M, Narayan, A \& Brearly, S. Assessing the professional performance of UK doctors: an evaluation of the utility of the General Medical Council patient and colleague questionnaires Quality and Safety in Health Care 2008 17; 187-193

17 Murphy, DJ, Bruce, DA, Mercer, SW, Eva, KW. The reliability of workplacebased assessment in postgraduate medical education and training: a national evaluation in general practice in the United Kingdom. Advances in Health Science Education 2008 doi 10.1007/s10459-008-9104-8

${ }^{18}$ Lelliot, P, Williams, R, Mears, A, Andiappan, M, Owen, H, Reading, P, Coyle, N \& Hunter, S. Questionnaires for 160-degree assessment of consultant psychiatrists: development and psychometric properties. British Journal of Psychiatry 2008 193; 156-160

19 Violato et al 2008 Changes in performance; a 5 year longitudinal study of participants in a multi-source feedback programme. Medical Education 2008 $42 ; 1007-1013$

${ }^{20}$ Archer, J, Norcini, J \& Davies, HA. Use of SPRAT for peer review of paediatricians in training. BMJ 2005 330; 1251-1253

${ }^{21}$ Whitehouse. A, Hassell, A, Wood, L, Wall, D, Walzman, M \& Campbell, I. Development and reliability testing of TAB a form for 360 degree assessment 
of Senior House Officers' professional behaviour, as specified by the General Medical Council. Medical Teacher. 2005. 27(3):252-8

${ }^{22}$ Archer, J, Norcini, J, Southgate, L, Heard, S \& Davies, H. mini-PAT (Peer Assessment Tool): A valid component of a national assessment programme in the UK? Advances in Health Sciences Education. 2008 May;13(2):181-92.

${ }^{23}$ Narayanan, A \& Greco, M. What distinguishes general practitioners form consultants, according to colleagues. Journal of Management and Marketing in Healthcare. 2007, 1; 80-87

${ }^{24}$ Hall, W, Violato, C, Lewkonia, R, Lockyer, J, Fidler, H, Toews, J, Jennett, P, Donoff, M \& Moores, D Assessment of physician performance in Alberta; the Physician Achievement Review. CMAJ 1999 161; 52-57

${ }^{25}$ Sargeant JM, Mann KV, Ferrier SN et al. Responses of rural family physicians and their colleague and co-worker raters to a multi-source feedback process: a pilot study. Academic Medicine 2003 78; S42-S44

${ }^{26}$ Violato, C, Lockyer, J \& Fidler, H. Changes in performance; a 5 year longitudinal study of participants in a multi-source feedback programme. Medical Education 2008 42; 1007-1013

${ }^{27}$ Murphy, DJ, Bruce, DA, Mercer, SW, Eva, KW. The reliability of workplacebased assessment in postgraduate medical education and training: a national evaluation in general practice in the United Kingdom. Advances in Health Science Education: Theory and Practice 2009 14; 219-232 
${ }^{28}$ Mercer, SW, Hatch, DJ, Murray, A, Murphy, DJ \& Eva, KW. Capturing patients' views on communication with anaesthetists: the CARE measure. Clinical Governance. 2008 13; 1298-137

${ }^{29}$ http://www.rcgp-curriculum.org.uk/nmrcgp/wpba/multi-source_feedback.aspx ${ }^{30}$ Griffin, E, Sanders, C, Craven, D \& King. J. A computerised feedback tool for personal and organizational development in general practice. Health Informatics Journal. 2000 6; 71-80

31 Narayanan, A and Greco, M. What distinguishes general practitioners from consultants, according to colleagues? Journal of Healthcare Management and Marketing. 2007 1; 80-87

${ }^{32}$ Greco, M, Cavanagh, M, Brownlea \& McGovern, J. The Doctors' Interpersonal Skills Questionnaire (DISQ): A validated instrument for use in GP training Education for General Practice. 1999, 10; 256-264

${ }^{33}$ Greco, M, Carter, M, Powell, R, Sweeney, K, Jolliffe, J and Stead, J. Impact of patient involvement in general practice. Education for Primary Care. 2006 $17 ; 486-95$

${ }^{34}$ Crossley, J, Humphris, G \& Jolly, B. Assessing health professionals. Medical Education. 2002. 36; 800-804

${ }^{35}$ General Medical Council. Good Medical Practice London: GMC 2006

${ }^{36}$ General Medical Council. GMC Principles, Criteria and Key Indicators for Colleague and Patient Questionnaires in Revalidation. London: GMC 2010. http://www.gmc- 
uk.org/static/documents/content/Revalidation_way_ahead_annex3.pdf (accessed 9 March 2010)

37 Verhulst, SJ, Colliver, JA, Paiva, RE \& Williams, RG. A factor analysis study of performance of first-year residents. Journal of Medical Education 61; 132134

${ }^{38}$ Department of Health. Research governance framework for health and social care. Second edition. London: Department of Health 2005 http://www.dh.gov.uk/en/Publicationsandstatistics/Publications/PublicationsP olicyAndGuidance/DH_4108962 [accessed 9 March 2010]

Corresponding Author: Professor Ajit Narayanan, Head of School of Computing and Mathematical Sciences, Auckland University of Technology, AUT Tower, 2-14 Wakefield St , Auckland 1142, New Zealand.

Address for correspondence: Private Bag 92006, Auckland 1142, New Zealand. Ph: + 6499219345 Fax: + 6499219944 